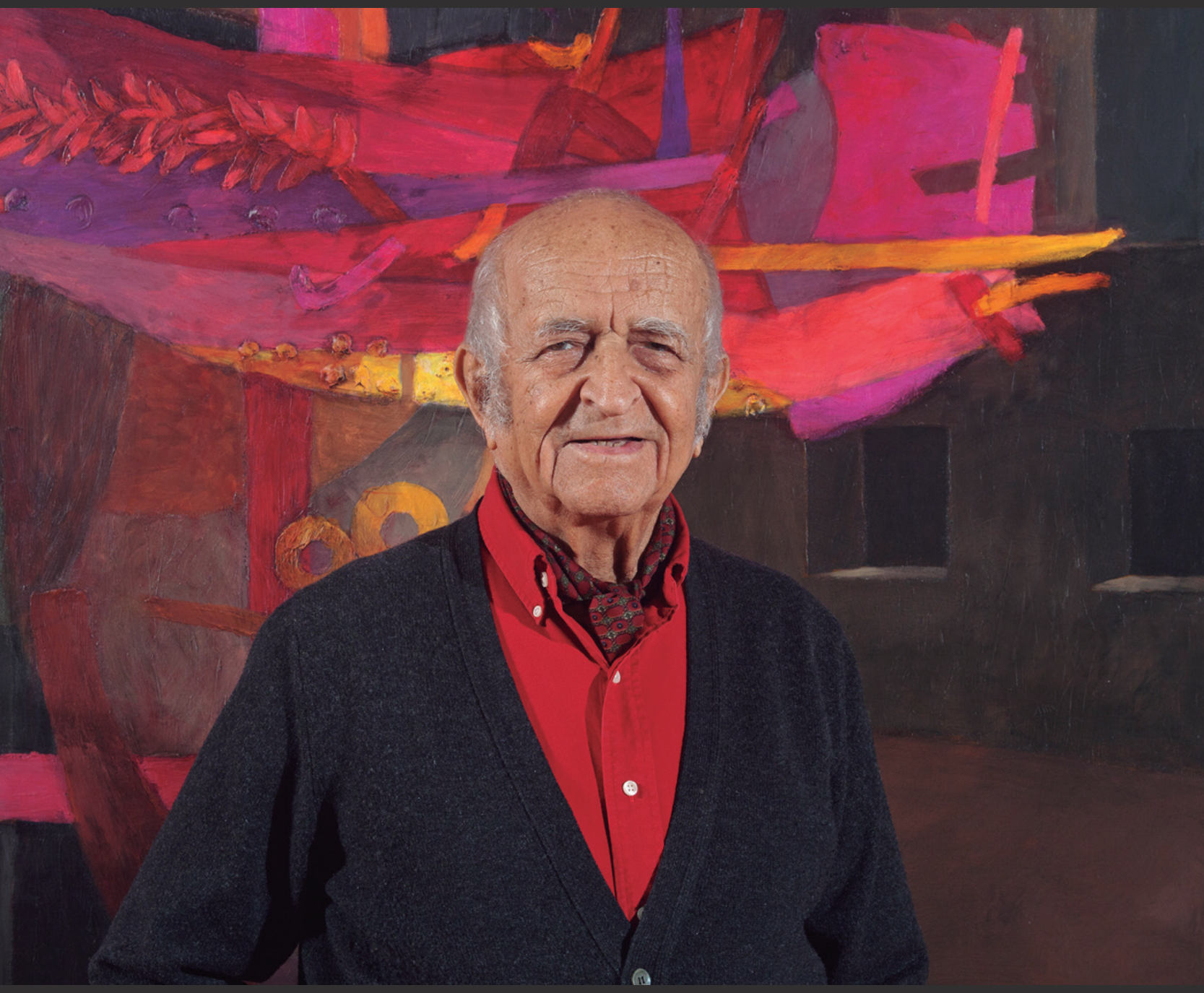

Fernando de Szyszlo

Foto: Alicia Benavides 


\section{Fernando de Szyszlo}

Ricardo Kusunoki Rodríguez

Curador Asociado del MALI

El 9 de octubre último, la noticia de la trágica muerte de Fernando de Szyszlo, a los noventa y dos años, junto con su esposa Liliana Yábar, ponía punto final a la carrera de una de las figuras fundacionales del modernismo peruano. De esta forma desaparecía, ante los ojos del gran público, la imagen paradigmática del artista peruano; la del creador que logró el éxito internacional sin perder los nexos con sus raíces locales. En efecto, las amplias repercusiones del acontecimiento daban cuenta de una trayectoria que superó los ámbitos especializados, para instalarse en la imaginación de amplios sectores de la población de nuestro país.

Sin duda, esta visibilidad -casi inédita en la historia del arte peruano- fue producto de una particular comprensión acerca del papel que tocaba desempeñar a los artistas en su condición de intelectuales. Desde los inicios de su carrera, Szyszlo asumió a la prensa como una palestra donde los temas artísticos y la defensa de las libertades civiles adquirían real proyección. En 1947 firmaba el manifiesto de la Agrupación Espacio, al tiempo que se convertía en asiduo colaborador del diario La Nación, vocero de la coalición democrática del presidente José Luis Bustamante y Rivero. Junto con Jorge Eduardo Eielson y Jorge Piqueras, entre otros, empezó a configurar una vanguardia modernista caracterizada por su beligerancia frente a la crítica oficial y por una obra con cierta vocación experimental. Antes de finalizar la década, Szyszlo no solo había incorporado a su trabajo las lecciones más recientes de Pablo Picasso, sino que, incluso, llegó a ensayar un lenguaje abiertamente primitivista, recreando la técnica de las telas pintadas Chancay.

Pero fue su partida a Europa en 1949, acompañado por su primera esposa, Blanca Varela, lo que marcó un auténtico punto de quiebre tanto en su trayectoria como en la propia escena local. En París -donde entabló amistad con figuras como André Breton, Julio Cortázar u Octavio Paz-, el artista encontró un estimulante ambiente intelectual mientras ingresaba en el ámbito de la no figuración. A su regreso a Lima, en 1951, presentó los trabajos que había realizado en la capital francesa; frente a la tibia recepción de estas piezas, Szyszlo ensayó un inteligente gesto provocador que convirtió a la abstracción en el centro del debate local. Su famosa declaración "no hay pintores en el Perú", constituía, en la práctica, la demanda de explicaciones a una escena artística que había permanecido casi de espaldas a los desarrollos internacionales.

Szyszlo mantuvo una permanente postura combativa a lo largo de la década de 1950, asociando la fortuna crítica de su obra a la de la abstracción peruana en su conjunto. Hacia fines de la misma década, cuando su pintura terminó de imponerse incluso entre la crítica 
local más reacia, se trasladó a Washington para trabajar en la Unión Panamericana junto al crítico cubano José Gómez Sicre. El contacto con el expresionismo norteamericano no solo sería un estímulo para ensayar mayores audacias formales, sino que también lo llevó a asumir de manera programática una inspiración ancestralista. Este giro, que alcanzó un momento estelar con la serie Apu Inca Atahualpaman (1963), terminó de posicionarlo exitosamente en la escena internacional.

Szyszlo adquirió así un lugar protagónico dentro de la búsqueda de un arte moderno y específicamente latinoamericano, igualmente opuesto a la descripción anecdótica de lo propio como al vanguardismo cosmopolita del pop art o el conceptualismo. El pintor defendió con apasionamiento aquella comprensión del arte, al que llegó a definir como "el encuentro visible de lo sagrado con la materia". Desde este punto de vista, resultaba coherente su oposición a las tendencias contemporáneas más experimentales, actitud que generó ocasionales fricciones al interior de la escena local. Consciente de su influencia en el ámbito público, esgrimió además una valiente defensa de la democracia frente a las complejas circunstancias políticas que vivió nuestro país en las últimas décadas.

Sin duda, el legado de Fernando de Szyszlo trasciende las fronteras de lo estrictamente artístico, para ocupar un lugar destacado en el panorama cultural del Perú contemporáneo. Se abre hoy la tarea de acometer un primer balance póstumo de sus aportes a la historia de nuestra precaria modernidad. 